\title{
Keratin expression in schwannoma; a study of 115 retroperitoneal and 22 peripheral schwannomas
}

\author{
Julie C Fanburg-Smith, Mourad Majidi and Markku Miettinen \\ Department of Soft Tissue Pathology, Armed Forces Institute of Pathology, Washington, DC, USA
}

\begin{abstract}
Schwannomas have been variably observed to be glial fibrillary acid protein (GFAP) and occasionally keratin positive, with antibodies reacting with multiple keratins (pankeratins, keratin cocktail (CK), but specific keratin polypeptides (K) have not been examined for in schwannoma. Since we observed CK positivity in retroperitoneal schwannomas, we wanted to study a large group of retroperitoneal and peripheral schwannomas with GFAP, CK and Ks to explore the frequency and biologic background of this finding.We immunohistochemically evaluated a large number of retroperitoneal $(n=115)$ and peripheral schwannomas $(n=22)$ for GFAP, 16 individual K and AE1/AE3 keratin cocktail. The great majority $(104 / 115,90 \%)$ of retroperitoneal schwannomas were positive for GFAP, and 72/104 (69\%) cases were positive for AE1/AE3, often extensively. Both markers highlighted the cellular Antoni $A$ areas, particularly adjacent to the capsule, myxoid or degenerative areas, and perivascularly. Most cases $87 / 104(84 \%)$ stained for both AE1/AE3 and GFAP at least focally. No tumors stained for keratins that were GFAP negative. None of the immunostains for individual $K$ showed positivity comparable to that obtained with AE1/AE3 CK. However, $62 \%$ were focally positive for high molecular weight K1 and 8/61 (13\%) for K7. None of the retroperitoneal schwannomas were positive for other keratins including K2, 4, 5, 8, 9, 10 and K14-20. Peripheral schwannomas showed GFAP-positivity in only three of 22 cases $(14 \%)$, and all were negative for keratins, both cocktail and individual $\mathrm{K}$. We conclude that crossreactivity of AE1/AE3 with other intermediate filament proteins, such as GFAP, as previously observed in brain and glioma tissue, probably accounts for the extensive keratin-positivity seen in some retroperitoneal schwannomas. However, focal expression of $\mathrm{K} 1$ and $\mathrm{K} 7$ cannot be ruled out. Keratin-positive schwannomas should not be confused with other keratin-positive tumors, such as sarcomatoid carcinoma, mesothelioma, and synovial sarcoma.

Modern Pathology (2006) 19, 115-121. doi:10.1038/modpathol.3800489
\end{abstract}

Keywords: schwannoma; keratin; GFAP; cross-reaction; immunohistochemistry; retroperitoneum; soft tissue

Soft tissue schwannomas have been observed to be sometimes glial fibrillary acid protein (GFAP) ${ }^{1-4}$ and occasionally keratins cocktail (CK) positive. ${ }^{4,5}$ No data exist on the possible expression of individual keratin polypeptides $(\mathrm{K})$ in these tumors. In nonneoplastic and neoplastic glia, keratin-positivity has

Correspondence: Dr JC Fanburg-Smith, MD, Department of Soft Tissue Pathology, Armed Forces Institute of Pathology, 6825 16th Street, N.W, Building 54, Rm G090 Washington, DC 20306-6000, USA.

E-mail: Fanburg@afip.osd.mil

The opinions and assertions contained herein are the expressed views of the authors and are not to be construed as official or reflecting the views of the Department of the Army or Department of Defense. Presented in part at the USCAP in San Francisco, CA, March 1999, published in part as an abstract: Fanburg-Smith JC, Miettinen $M$ Keratin reactivity in retroperitoneal schwannoma: a study of 90 cases. Modern Pathology 1999;12(1):abstract \# 39. Received 13 April 2005; revised 30 June 2005; accepted 2 August 2005 been observed and postulated to represent crossreactivity with other proteins, such as GFAP, especially in paraffin-embedded material. ${ }^{6,7}$ We have observed common keratins (pankeratins, AE1/AE3) reactivity in retroperitoneal schwannomas and suspect that this may represent crossreactivity of AE1/AE3 keratin cocktail with GFAP. To determine the frequency and biologic explanation for the positivity for cytokeratin cocktail in retroperitoneal schwannoma, we studied a large group of retroperitoneal and peripheral schwannomas with GFAP, $\mathrm{CK}$, and various $\mathrm{K}$.

\section{Materials and methods}

Retroperitoneal $(n=115)$ and peripheral $(n=22)$ schwannomas were retrieved from the AFIP Soft Tissue Registry. Peripheral tumors were required to be from the head and neck or extremities, with 
classic schwannoma morphology. The axial schwannomas were required to be from a central location; all were retroperitoneal. The tumors were immunohistochemically evaluated from available paraffinembedded material or unstained slides for GFAP, AE1/AE3 keratin cocktail, and a broad array of antibodies, including S100 protein, HMB45, and nearly all individual keratin polypeptides. The antibodies, pretreatments, dilutions, and sources are listed in Table 1. Keratin numbering was according to Moll et al. ${ }^{8,9}$ Immunostains were performed using Dako Envision + detection system with DAB as the chromogen, or with Dako LSAB + kit. Heat-based epitope retrieval with an EDTAbuffer (372 mg of Na-EDTA/L at $\mathrm{pH}$ 8.0) was used provided by a vegetable steamer. Positive and negative controls were used throughout. Two authors (JCFS, MM) reviewed and concurred on the morphologic and immunohistochemical results. Staining was scored as follows: $0=$ negative; $1+$ $=$ focal $(<50 \%)$ weak staining, $2+=$ focal, strong staining, $3+=$ diffuse $(>50 \%)$ weak staining, $4+$ $=$ diffuse, strong staining. We further scored the correlation between the GFAP and AE1/AE3 reactivity, as follows: $1=$ correlates well (similar level of immunoreactivity); $2=$ correlates but AE1/AE3 is more focal than GFAP; $3=$ no correlation (GFAP positive, but AE1/AE3 negative).

Western blot was attempted using frozen tissue lysates for a retroperitoneal schwannoma, and controls of brain tissue and skin (courtesy Walter Reed Army Medical Center), and male placenta (courtesy Mr Jacob D Smith, Fairfax Hospital, Fairfax, VA, USA), by dounce homogenization in icecold buffer containing 1\% NP-40, $50 \mathrm{mM}$ Tris $(\mathrm{pH}$
7.5), $50 \mathrm{mM}$ sodium chloride, $2 \mathrm{mM}$ sodiumorthovanadate, $5 \mathrm{mM}$ EDTA, $8 \mathrm{M}$ urea, $5 \mu \mathrm{g} / \mathrm{mg}$ aprotinin, $5 \mu \mathrm{g} / \mathrm{mg}$ leupeptin, and $50 \mu \mathrm{g} / \mathrm{mg}$ phenylmethylsulfonyl fluoride, and centrifuged for $10 \mathrm{~min}$ at $10000 \mathrm{~g}$. Then the pellets were washed with the same buffer to remove contaminants and incubated in $100 \mu \mathrm{l}$ of SDS-PAGE loading buffer containing $0.1 \% \beta$-mercaptoethanol. The samples were heated to $95^{\circ} \mathrm{C}$ for $5 \mathrm{~min}$, and centrifuged at maximum speed. Protein concentrations of the tissue lysates were determined by the Bradford method, and the samples were normalized to $50 \mathrm{mg}$ of proteins/ sample, before loading on 10\% SDS-PAGE gel. The proteins were transferred to nitrocellulose, and blocked in $5 \%$ dried milk, $10 \mathrm{mM}$ Tris HCL, pH 7.4, and $10 \mathrm{mM} \mathrm{NaCl}$ for $1 \mathrm{~h}$. After washing filters briefly, antisera diluted in $10 \mathrm{mM}$ Tris HCL, $\mathrm{pH}$ 7.4, and $10 \mathrm{mM}$ NaCL were added and the incubation was carried out for $1 \mathrm{~h}$ at room temperature. Filters were washed three times (15 min each wash) with phosphate-buffered saline, $0.05 \%$ Tween-20 and reacted for $1 / 2 \mathrm{~h}$ with horse-radish-coupled secondary antibody and bands were visualized by enhanced chemilumunescence reagent (ECL) (Amersham Pharmacia Biotech). Controls included the brain, skin, and placental tissue, processed by the same techniques. For molecular studies, goat polyclonal antibody to GFAP, and mouse monoclonal antibodies to CK7, 8, and 18 were purchased from Santa Cruz Biotechology Inc. (CA, USA); mouse monoclonal antibodies to AE1, and AE3 were obtained from Zymed Laboratories Inc. (CA, USA) and mouse monoclonal antibody to CK1 was acquired from Novocastra Laboratories Ltd, UK.

Table 1 Antibodies (clones), sources, dilutions, and pretreatments

\begin{tabular}{|c|c|c|}
\hline Antibody & Source & Dilution \\
\hline S100 protein (polyclonal) & Dako Corporation & 1:800 (Carpinteria, CA, USA) \\
\hline GFAP (polyclonal) ${ }^{\mathrm{a}}$ & Dako Corporation & $1: 1000$ \\
\hline $\mathrm{AE} 1 / \mathrm{AE}^{\mathrm{a}}$ & Dako Corporation & $1: 2$ \\
\hline $\mathrm{K}^{\mathrm{a}}$ & Dako Corporation & $1: 200$ \\
\hline $\operatorname{Cam} 5.2^{\mathrm{a}}$ & Becton Dickinson & 1:200 (San Jose, CA, USA) \\
\hline $34 \beta$ E12 a high molecular weight $1,5,10,11,14 / 15$ & Enzo Diagnostics (Syosset, NY, USA) & $1: 40$ \\
\hline CK5/6 (clone D5/26 B4) ${ }^{\mathrm{b}}$ & Boehringer Mannheim & 1:20 (Indianapolis, IN, USA) \\
\hline $\mathrm{K} 1^{\mathrm{b}}(34 \mathrm{bB} 4)$ & Novocastra & $1: 40$ \\
\hline $\mathrm{K} 4^{\mathrm{b}}(6 \mathrm{~B} 10)$ & Novocastra & $1: 100$ \\
\hline K6 ${ }^{\mathrm{b}}(\mathrm{LHK} 6 \mathrm{~B})$ & Novocastra & $1: 40$ \\
\hline K10 ${ }^{\mathrm{b}}$ (LHP1) & Novocastra & $1: 50$ \\
\hline $\mathrm{K} 13^{\mathrm{b}}(\mathrm{KS}-1 \mathrm{~A} 3)$ & Novocastra & $1: 100$ \\
\hline K15 ${ }^{\mathrm{b}}$ (LHK15) & Novocastra & $1: 50$ \\
\hline K16 ${ }^{\mathrm{b}}$ (LL002) & Novocastra & $1: 40$ \\
\hline $\mathrm{K} 17^{\mathrm{b}}(\mathrm{E} 3)$ & Novocastra & $1: 40$ \\
\hline K18 ${ }^{\mathrm{b}}(\mathrm{DC}-10)$ & Novocastra & $1: 40$ \\
\hline K19b (RCK 108) & Dako Corporation & $1: 50$ \\
\hline $\mathrm{K} 20^{\mathrm{b}}(\mathrm{Ks} 20.8)$ & Zymed & $1: 50$ \\
\hline
\end{tabular}

$\mathrm{GFAP}=$ glial fibrillary acidic protein; $\mathrm{CK}=$ cytokeratin .

${ }^{\mathrm{a}}$ Pretreatment with protease (type VIII) for $2 \mathrm{~min}$ at $37^{\circ} \mathrm{C}$.

${ }^{\mathrm{b}}$ Microwave (heat) pretreatment, adjusted to near boiling in EDTA buffer (372 mg/L sodium EDTA/a) for $20 \mathrm{~min}$ at $\mathrm{pH}$ 8.0, followed by a $40 \mathrm{~min}$ cooling period. 


\section{Results}

A total of 115 cases of retroperitoneal schwannoma and 22 cases of peripheral schwannoma were included in the study. Of 90 retroperitoneal schwannoma cases with available demographics, there were 30 male and 60 female cases. Patient ages ranged from 16 to 84 years (mean 49.5 years); the tumor sizes ranged from $2-27 \mathrm{~cm}$ (mean $10.2 \mathrm{~cm}$ ). All tumors, both retroperitoneal and peripheral were classic or cellular schwannomas by previously established criteria. ${ }^{10}$ The peripheral schwannomas were mainly classic and the retroperitoneal schwannomas mainly cellular (Figure 1). No tumor contained epithelial elements as described in the rare glandular schwannoma. All schwannomas were diffusely and strongly positive for S100 protein (Figure 2) and negative for HMB45.

\section{GFAP and AE1/AE3}

Of the peripheral schwannomas, only three of 22 were positive for GFAP and all were negative for
AE1/AE3 keratin cocktail, so no further cytokeratins were evaluated on these tumors.

Of the retroperitoneal schwannomas, 104/115 cases $(90 \%)$ were positive for GFAP $(14+)$ (Figure

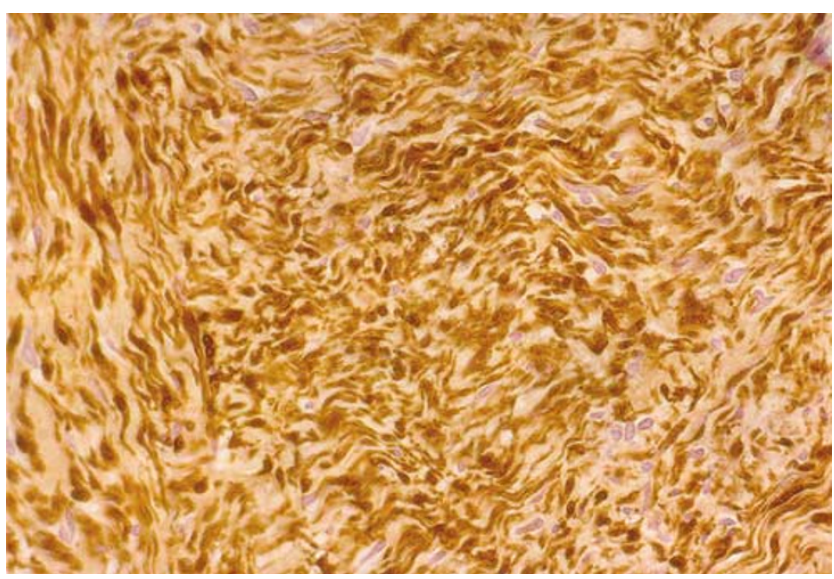

Figure 2 All cases studied were strongly, diffusely positive for S100 protein.
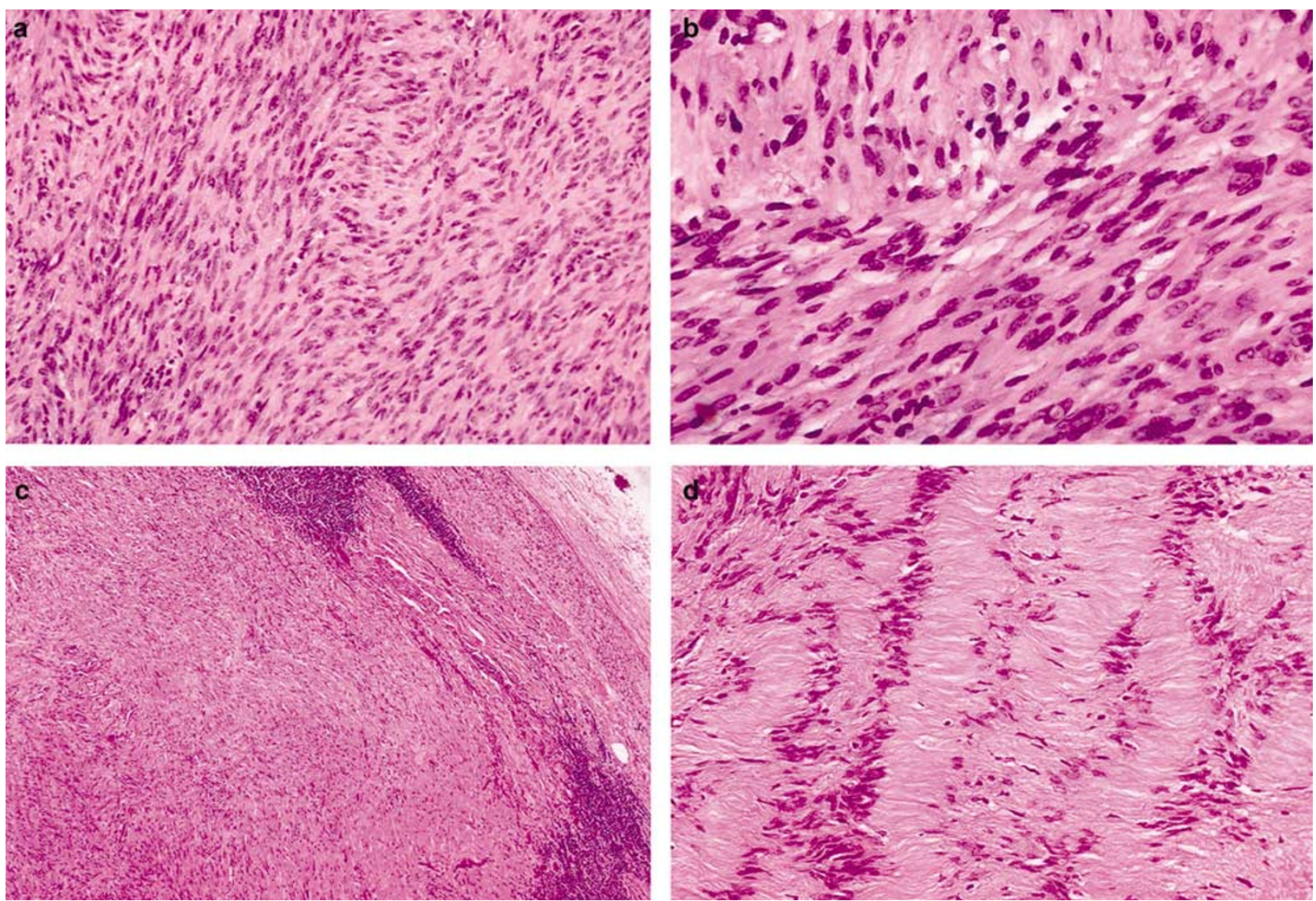

Figure 1 Retroperitoneal cellular schwannoma morphology could easily be confused with malignant spindle cell neoplasms, especially when keratins positive, and when there are Antoni A areas only without Verocay body formation, a fascicular growth pattern, cellularity, large cell size, mitotic activity, and pleomorphism (a, b). The additional morphologic feature of pericapsular lymphocytic cuffing of cellular schwannoma (c) may help separate schwannoma from these other retroperitoneal spindle cell neoplasms. Peripheral classic schwannoma with wavy nuclei and Verocay bodies (d). 


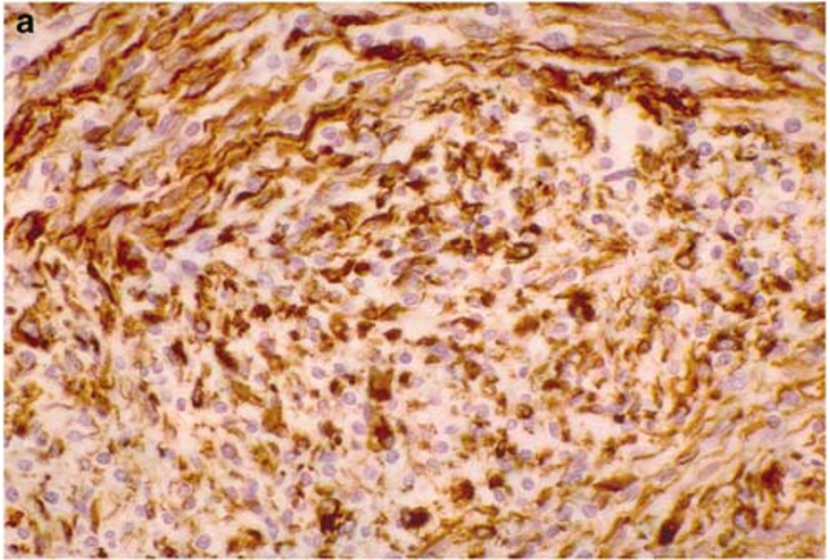

b

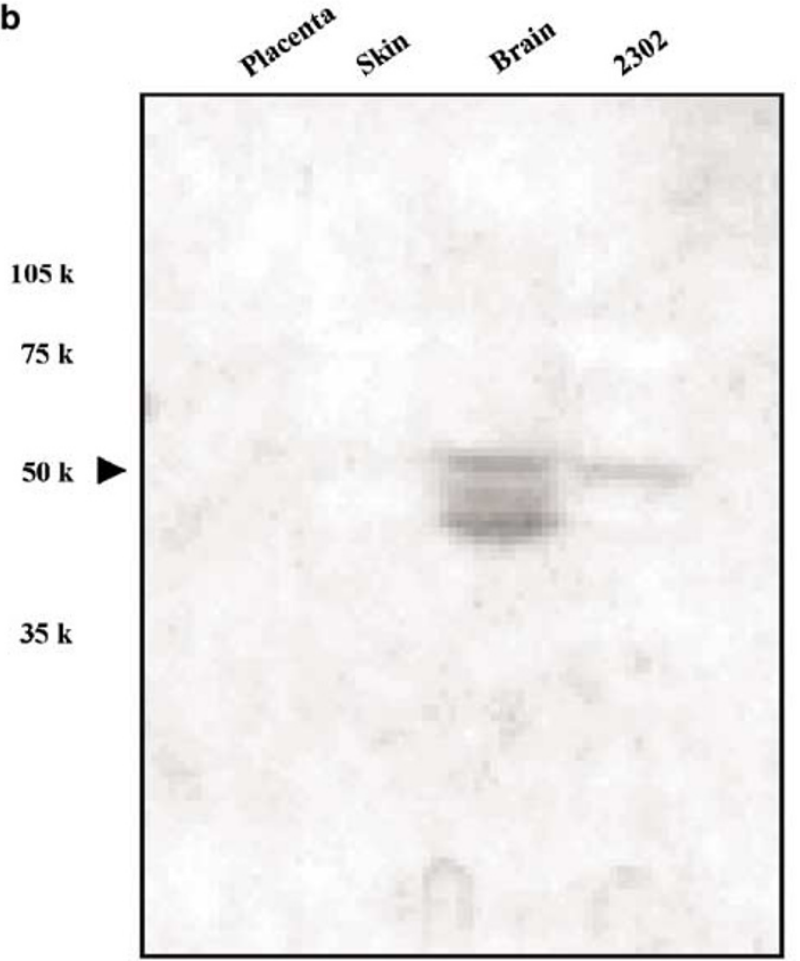

Figure 3 In all, $90 \%$ of the retroperitoneal and $14 \%$ of the peripheral schwannomas were positive for GFAP $(1-4+)$ by immunohistochemistry (retroperitoneal schwannoma, (a)). Detection of GFAP proteins by Western blot demonstrates expression of GFAP in a retroperitoneal schwannoma, and brain tissue but not in the placenta or skin lysates. The position of molecular mass markers, are shown at the left (b).

3). In all, $71 / 104(68 \%)$ cases showed cytoplasmic AE1/AE3 positive in spindled tumor cells $(1-4+)$ (Figure 4). Both GFAP and keratins highlighted the cellular Antoni A areas, particularly adjacent to the capsule and myxoid or degenerated areas. Positivity was often remarkably strongly perivascular. In nearly half of the cases, $45 / 104(43 \%)$ the patterns obtained with GFAP and AE1/AE3 antibodies were closely matching (score 1), whereas in 41/104 (39\%) cases there was less cytokeratin than GFAP staining (score 2). In 18 cases (17\%), there was no clear
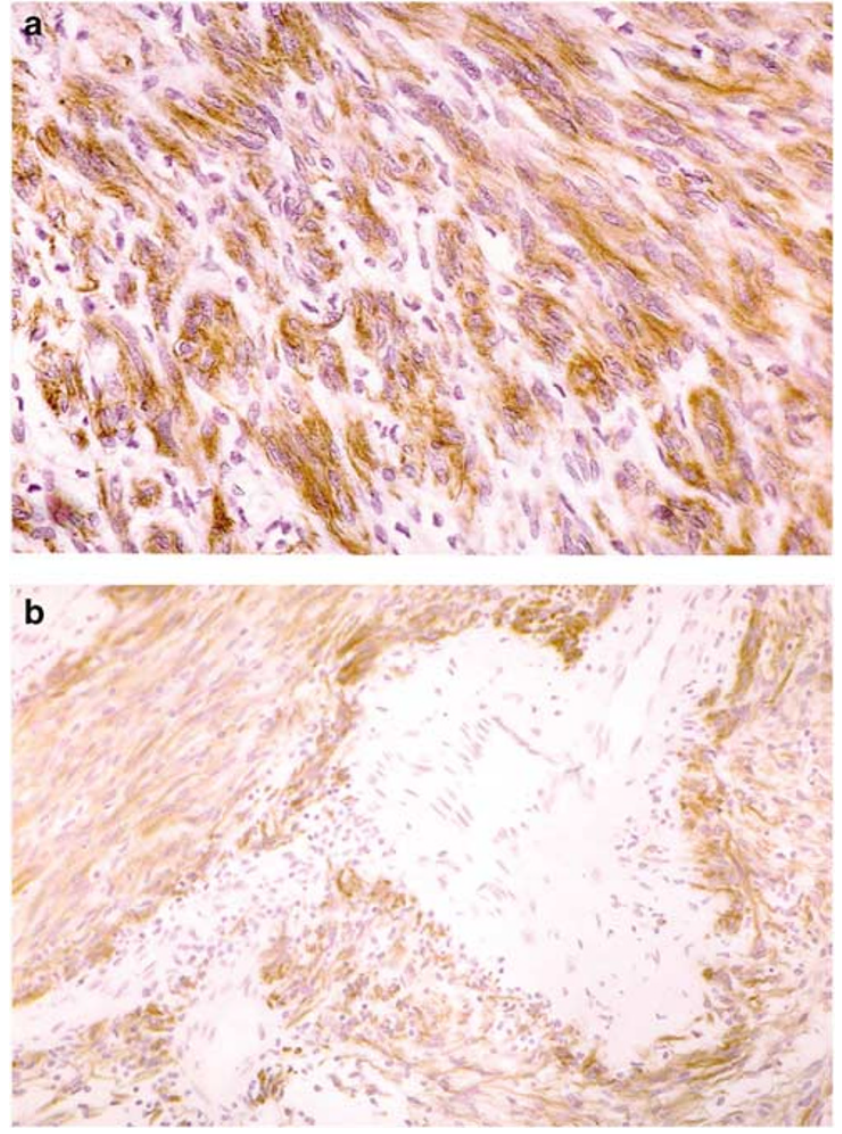

Figure 4 In total, 62\% of the retroperitoneal schwannomas (and none of the peripheral schwannomas) were positive for AE1/AE3 $(1-4+)$; with a similar distribution to GFAP, keratin cocktail concentrated adjacent to the capsule, myxoid or degenerative areas, and in a perivascular distribution $(\mathbf{a}, \mathbf{b})$.

correlation between GFAP and AE1/AE3 immunostains. GFAP was determined in retroperitoneal schwannoma by Western blot (Figure 3). Keratins could not be conclusively demonstrated by Western blot technique.

\section{Individual Keratin Polypeptides}

Study of a large array of antibodies covering nearly all individual keratin polypeptides, except K3, K11, and $\mathrm{K} 12$, on these schwannomas resulted in most keratin polypeptide antibodies failing to give any staining in schwannoma cells. Endothelial and smooth muscle reactivity for $\mathrm{K} 1$ and $\mathrm{K} 7$ was detected as previously described. ${ }^{11}$ Of the keratin cocktail-positive tumors, 8/61 cases (13\%) were focally positive for K7 (Figure 5). In many of these cases, contribution by perivascular smooth muscle elements cell could not be definitively ruled out. K1 was detected in 24/39 (62\%) of cases, usually focally. No tumor was positive for high molecular weight keratins (34 $\beta$ E12), K4, K5, K6, K8, K10, K13-20. Again, individual keratin peptides could 

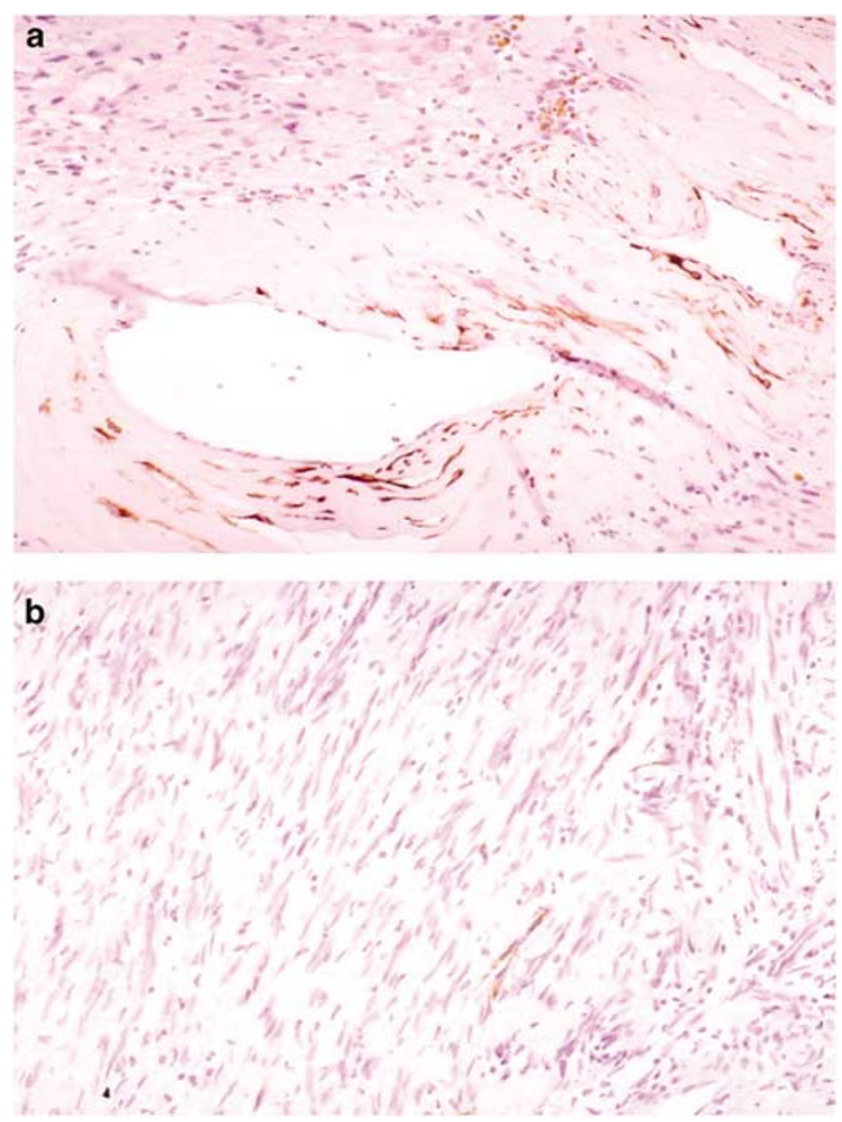

Figure 5 Focal CK7 positivity in eight of the retroperitoneal schwannomas was largely attributed to perivascular myopericytic cells staining positively and difficult to distinguish from possible true spindle cell tumor staining (a, b).

Table 2 Retroperitoneal schwannoma immunostain results, summarized

\begin{tabular}{lcc}
\hline Antibody & $\begin{array}{c}\text { Number positive/ } \\
\text { number stained }\end{array}$ & $\begin{array}{c}\text { Percentage } \\
\text { positive (\%) }\end{array}$ \\
\hline S100 protein & $90 / 90$ & 100 \\
GFAP & $104 / 115$ & 90 \\
AE1/AE3 & $71 / 104$ & 69 \\
34 E12 & $0 / 23^{\mathrm{a}}$ & 0 \\
CK1 & $24 / 39^{\mathrm{a}}$ & 62 \\
CK4 & $0 / 39^{\mathrm{a}}$ & 0 \\
CK5/6 & $0 / 11^{\mathrm{a}}$ & 0 \\
CK6 & $1 / 24^{\mathrm{a}, \mathrm{b}}$ & 4 \\
CK7 & $8 / 61^{\mathrm{a}, \mathrm{b}}$ & 13 \\
Cam 5.2 (CK8/18) & $0 / 58^{\mathrm{a}}$ & 0 \\
CK10 & $0 / 24^{\mathrm{a}}$ & 0 \\
CK13 & $0 / 15^{\mathrm{a}}$ & 0 \\
CK14 & $3 / 24^{\mathrm{a}, \mathrm{b}}$ & 13 \\
CK15 & $0 / 39^{\mathrm{a}}$ & 0 \\
CK16 & $0 / 39^{\mathrm{a}}$ & 0 \\
CK17 & $0 / 39^{\mathrm{a}}$ & 0 \\
CK18 & $0 / 24^{\mathrm{a}}$ & 0 \\
CK19 & $0 / 35^{\mathrm{a}}$ & 0 \\
CK20 & $0 / 24^{\mathrm{a}}$ & 0 \\
\hline
\end{tabular}

${ }^{\mathrm{a} O n l y}$ evaluated on AE1/AE3 positive-tumors.

${ }^{b}$ Difficult to separate from small vessel staining (myopericytic and smooth muscle cells) in highly vascular areas (Figure 5, Ref. ${ }^{11}$ ). not be conclusively demonstrated by Western blots. The immunostaining results are summarized in Table 2.

\section{Discussion}

While many observers have described GFAP ${ }^{1-3}$ and keratin $^{4,5}$ immunoreactivity in soft tissue schwannoma, simultaneous reactivity of GFAP and cytokeratins has been only rarely reported. One study found that only one of 27 peripheral schwannomas to be positive for both cytokeratin and GFAP but did not analyze individual keratins. ${ }^{4}$ In the present study, we report extensive coexpression of GFAP and keratin AE1/AE3 cocktail in $69 \%$ of our retroperitoneal schwannomas, but not in our peripheral schwannomas.

We propose that this keratin expression in schwannoma is due to cross-reactivity with GFAP, since both keratins and GFAP are partially homologous proteins. The GFAP and keratins reactivity appeared to be collocated to exact sites histologically within these tumors, with most mismatches only showing more GFAP than keratins. There were no tumors staining for keratins that were GFAP negative. Based on our observations, peripheral schwannomas are less likely than retroperitoneal schwannoma to express keratins since they are also less likely to express GFAP. Earlier observations on GFAP-positive schwannomas also suggest that paraspinal, retroperitoneal, and mediastinal schwannomas may be more often GFAP-positive than peripheral tumors. ${ }^{4}$ We have observed this finding in our practice as well. The reason for such a differential GFAP expression in schwannomas is unclear. It is theoretically possible that GFAP is more widespread in larger, central nerve trunks than in smaller, peripherally located ones, but additional histologic investigations would have to be made to support this observation.

Additional support to a theory of crossreactivity between GFAP and keratins is that Western blotting of schwannoma did not appear to show individual keratins within these tumors, with the possible exception of $\mathrm{K} 7$ and $\mathrm{K} 1$. Therefore, the pankeratins antibody binding could represent crossreactivity with GFAP. Extensive keratin-positivity was seen in retroperitoneal schwannomas with AE1/AE3 keratin cocktail in this study. However, there was only limited keratin-positivity detected with a large panel of antibodies to individual keratins. Our study covered a great majority of different keratin polypeptides, only excluding the corneal keratins (K3, K12) and K11; there are no antibodies to the latter keratin (K11), to our knowledge. The great discrepancy between the extensive AE1/AE3 keratin-positivity and scant positivity for individual keratins further supports the possibility of crossreactivity of AE1/AE3 with epitopes on other related molecules, such as GFAP. 
Crossreactivity has been suggested for coexpression of GFAP and keratins in normal brain and in brain tumors. Following the initial reports of AE1/ AE3 keratin cocktail positive gliomas in formalinfixed and paraffin-embedded tissue, ${ }^{12,13}$ several studies have critically analyzed the biologic background of apparent keratin expression in normal brain tissue and gliomas. Franke et $a l^{14}$ noted that snap-frozen brain did not show AE1/AE3 keratinpositivity. Bacchi et $a l^{6}$ conducted a series of experiments, observing that keratin-positivity in normal brain and gliomas was detected with AE1/ AE3 cocktail only in formalin-fixed and paraffinembedded, enzymatically digested tissue but not in methacarn-fixed tissue; it was somewhat unclear whether frozen, unfixed tissues were analyzed in this study. Also, no K8 was detected by Western blotting with CAM5.2 antibody. These authors concluded that AE1/AE3 keratin-positivity did not represent true keratin expression. ${ }^{6}$

Kriho et $a l^{7}$ examined normal brain and astrocytomas for keratin expression, and found that both were immunoreactive for AE3 but not AE1 in cryostat sections. Also, immunoreactivity for KS1A3 reacting with K13 was found in grade II-IV gliomas but not in normal brain. However, they found brain tissue keratin-negative in immunoblotting with AE3, except for occasional positive bands at 53 and $65 \mathrm{kDa}$, consistent with the highest molecular weight epidermal keratins, and interpreted it as epidermal keratin contamination. They also then concluded that AE3 positivity in brain represents crossreactivity with other nonkeratin proteins, such as GFAP.

Technical factors related to immunostaining procedures have also been implicated on probable falsepositive keratin and other intermediate filament immunostaining in human brain and gliomas. In the study of Franke et $a l^{14}$ on snap-frozen tissues, several monoclonal keratin antibodies, for example KA4 (covering K14, K15, K16, K19) gave positive staining in different gliomas, and to lesser degree, in reactive or normal astroglia. The authors concluded that inadvertent binding of rabbit gamma $\mathrm{G}$ immunoglobulins during APAAP immunostaining procedure and relative overdose of primary antibody could lead to cross-reactions between keratins and other proteins.

There are some central nervous system tumors in which true keratins expression may be present. Keratin-positivity confirmed in glioma cell lines by Western blotting and Northern analysis and CAM5.2 (K8 antibody) positivity in some malignant gliomas ${ }^{15}$ can represent true keratin expression, comparable to the acquisition of K8 and K18 in transformed cells through deregulation of keratin expression, as previously reported for cultured transformed fibroblasts. ${ }^{16}$

The extensive AE1/AE3 keratin cocktail positivity in retroperitoneal schwannomas, without matching positivity with any of the antibodies to individual keratins, together with observations on AE1/AE3 positivity in normal brain without biochemical detection of keratins, suggests that cross-reaction of AE1/AE3 with other proteins, especially GFAP, significantly contributes to AE1/AE3 immunoreactivity in schwannomas. The rationales of crossreactions include alteration of keratin epitopes by enzymatic digestion, perhaps by unmasking or artefactual revealing of epitopes common to these filament proteins. That such common epitopes exists is suggested by reactivity of some antibodies with all classes of intermediate filament proteins. ${ }^{17}$ The clustering of genes for many keratins (especially type I) and GFAP on chromosome $17 q 21^{18}$ may be a sign of their evolutional relatedness and explanation for partial homology.

The only exceptions of individual keratin staining include K7 and K1. Focal K7 positivity was found in some retroperitoneal schwannomas in this study; this keratin seems to be present in endothelial cells as well. ${ }^{11}$ We cannot rule out the possibility that K7 could truly be focally expressed in retroperitoneal schwannomas. K1-positivity was observed in $62 \%$ of retroperitoneal schwannomas in this study, usually focally, raising the possibility of true expression of this keratin. Some previous studies have indeed noted this keratin in brain tissue, ${ }^{19}$ although in other studies the presence of immunoblotting bands at $63-65 \mathrm{kDa}$, consistent with $\mathrm{K} 1$, was ascribed to human epidermal keratin contamination. $^{7}$

As retroperitoneal schwannomas are often keratin-positive with AE1/AE3 cocktail, it is important to be aware of this fact and to distinguish these tumors from other keratin-positive spindle cell tumors, especially malignant ones such as spindle cell carcinoma, mesothelioma, and keratin-positive sarcomas, especially synovial sarcoma. The large size and high cellularity of many retroperitoneal schwannomas may contribute to such a potential confusion. Strong, uniform S100-protein, and GFAP positivity will help to separate retroperitoneal schwannoma from carcinoma and mesothelioma, most of which are negative. Some malignant peripheral nerve sheath tumor (MPNST) demonstrate keratins, especially $\mathrm{K} 8$ and $\mathrm{K} 18,{ }^{20}$ but spindle cell MPNST are generally only focally positive for S100 protein. Synovial sarcoma can be focally positive for S100 protein, but more often residual nerve twigs stain for S100 protein in this tumor. Epithelioid sarcoma is negative for S100 protein and GFAP. Primitive neuroectodermal tumor is only rarely spindled but could be focally rarely positive for S100 protein, GFAP, and keratins, but the morphology and strong membrane staining for CD99 would separate this generally small blue cell tumor from the pink-spindled cell tumor of schwannoma.

In conclusion, the great majority of retroperitoneal schwannomas $(90 \%)$ and minority of peripheral ones are GFAP-positive. Extensive keratin cocktail 
AE1/AE3 positivity observed in a majority of retroperitoneal schwannomas largely parallels GFAPpositivity in these tumors. Since there is a significant discrepancy between the prominent AE1/AE3 keratin positivity and scant keratin detection with a large panel of antibodies covering most of the individual keratins, AE1/AE3 positivity in schwannomas may represent crossreactivity with GFAP, as previously suggested for normal glial tissue. However, focal expression of $\mathrm{K} 1$ and $\mathrm{K} 7$ cannot be ruled out. Keratin-positive schwannomas should not be confused with sarcomatoid carcinomas, mesotheliomas, or keratin-positive sarcomas.

\section{References}

1 Memoli VA, Brown EF, Gould VE. Glial fibrillary acidic protein immunoreactivity in peripheral nerve sheath tumors. Ultrastruct Pathol 1984;7:269-275.

2 Gould VE, Moll R, Moll I, et al. The intermediate filament complement of the spectrum of nerve sheath neoplasms. Lab Invest 1986;55:463-474.

3 Kawahara E, Oda Y, Ooi A, et al. Expression of glial fibrillary acidic protein (GFAP) in peripheral nerve sheath tumors. Am J Surg Pathol 1988;12:115-120.

4 Gray MH, Rosenberg AE, Dickersin GR, et al. Glial fibrillary acidic protein and keratin expression by benign and malignant nerve sheath tumors. Hum Pathol 1989;20:1089-1096.

5 Guarino M. Plexiform schwannoma. Immunohistochemistry of Schwann cell markers, intermediate filaments and extracellular matrix components. Pathol Res Pract 1993;189:913-920.

6 Bacchi CE, Zarbo RJ, Jiang JJ, et al. Do glioma cells express cytokeratin? Appl Immunohistochem 1995;3:45-54.

7 Kriho VK, Yang H-Y, Mostkal JR, et al. Keratin expression in astrocytomas: an immunofluorescent and biochemical reassessment. Virchows Arch 1997;431: 139-147.

8 Moll R, Franke WW, Schiller DL, et al. The catalog of human cytokeratins: patterns of expression in normal epithelia, tumors and cultured cells. Cell 1982;31:11-24.
9 Moll R, Lowe A, Laufer J, et al. Cytokeratin 20 in human carcinomas. A new histodiagnostic marker detected by monoclonal antibodies. Am J Pathol 1992;140:427-447.

10 Scheithauer BW, Woodruff JM, Erlandson RA. Tumors of Peripheral Nervous System. Armed Forces Institute of Pathology: Washington, DC, 1999.

11 Miettinen M, Fetsch JF. Distribution of keratins in normal endothelial cells and a spectrum of vascular tumors: implications in tumor diagnosis. Hum Pathol 2000;31:1062-1067.

12 Cosgrove M, Fitzgibbons PL, Sherrod A, et al. Intermediate filament expression in astrocytic neoplasms. Am J Surg Pathol 1989;13:141-145.

$13 \mathrm{Ng} \mathrm{H}-\mathrm{K}$, Lo STH. Cytokeratin immunoreactivity in gliomas. Histopathology 1989;14:359-368.

14 Franke FE, Schachenmayr W, Osborn M, et al. Unexpected immunoreactivities of intermediate filament antibodies in human brain and brain tumors. Am J Pathol 1991;139:67-79.

15 Cosgrove MM, Rich KA, Kunin SA, et al. Keratin intermediate filament expression in astrocytic neoplasms: analysis by immunocytochemistry, Western blot, and Northern hybridization. Mod Pathol 1993; 6:342-347.

16 Knapp AC, Franke WW. Spontaneous losses of control of cytokeratin gene expression in transformed, nonepithelial human cells occurring at different levels of regulation. Cell 1989;59:67-79.

17 Pruss RM, Mirsky R, Raff MC, et al. All classes of intermediate filaments share a common antigenic determinant defined by a monoclonal antibody. Cell 1981;27(Part 2):419-428.

18 Brownell E, Lee AS, Pekar SK, et al. Glial fibrillary acid protein, an astrocytic specific marker, maps to human chromosome 17. Genomics 1991;10:10871089.

19 Franko MC, Gibbs Jr CJ, Rhoades DA, et al. Monoclonal antibody analysis of keratin expression in the central nervous system. Proc Natl Acad Sci USA 1987;84: 3482-3485.

20 Miettinen M. Keratin subsets in spindle cell sarcomas. Keratins are widespread but synovial sarcoma contains a distinctive keratin polypeptide pattern and desmoplakins. Am J Pathol 1991;138:505-513. 